\title{
PENGEMBANGAN HUTAN PINUS MASYARAKAT BERBASIS KEMITRAAN SEBAGAI MODEL PEMBERDAYAAN MASYARAKAT SEKITAR HUTAN
}

\author{
HERU PRASTAWA, ZAINAL FANANI R., DAN HERY SULIANTORO \\ Teknik Industri, Universitas Diponegoro \\ E-mail: Heru.prastawa@gmail.com
}

\begin{abstract}
ABSTRAK
Kabupaten Pekalongan adalah salah satu kabupaten di Provinsi Jawa Tengah yang memiliki area hutan yang relative luas, dan termasuk hutan masyarakat. Hutan masyarakat dalam beberapa tahun telah ditanami dengan pohon pinus, populasi pohon pinus dan sebagainya di daerah ini berkisar 400.000 pohon. Sebagian besar dari populasi tersebut tidak digunakan secara optimal oleh masyarakat, sehingga perlu adanya usaha untuk mengiplementasikan pengembangan potensi tersebut. Salah satu bentuk pengembangan yang dapat dilakukan adalah pemrosesan getah pohon pinus menjadi produk Gondorukem, di mana Gondorukem adalah salah satu jenis bahan material dasar industry, termasuk industry batik sebagai sektor industri yang potensial di Kabupaten Pekalongan. Dalam upaya untuk menyelesaikan masalah pada penelitian ini, menggunakan pendekatan klaster industry. Pendekatan ini menggunakan alat bantu dan perangkat data proses, termasuk analisa internal dan eksternal komunitas lingkungan hutan pinus, analisa SWOT, penentuan keputusan menggunakan Analitycal Network Process (ANP), analisa Competitiveness Diamond, dan model formulasi strategi berdasar analisa sebelumnya dan analisa pendukung. Dari beberapa perangkat diharapkan untuk memperoleh formulasi strategi yang tepat dan pelaksanaan pengembangan potensi hutan pinus publik di Kabupaten Pekalongan dalam rangka mendukung peningkatan daya saing Kabupaten Pekalongan.
\end{abstract}

Kata kunci: hutan masyarakat, gondorukem, klaster industry, analisa SWOT, analitycal network process (ANP)

\begin{abstract}
Pekalongan Regency is one regency in the region of Central Java Province has a forest area is relatively large, including public forests. Public forest for several years has been planted by pine trees, pine trees and even the population in the region has reached 400,000 trees. Such large populations have not utilized optimally by the public, so the effort required to implement a development of that potential. One development that can be done is by processing the sap of pine into Gondorukem products, which Gondorukem is one of several types of raw materials industries, including batik industry is an important industrial sector in Pekalongan Regency. In an attempt to resolve the problem in this research, use industry cluster approach. This approach uses several instruments and data processing devices, including analysis of internal and external environment pine forest community, SWOT analysis, decision-making with Analitycal Network Process (ANP), analysis of the competitiveness diamond approach and strategy formulation model taking into account some previous analysis and analysis supporters. Of some devices is expected to obtain an appropriate strategy formulation and implementation of the development potential of the public pine forest in Pekalongan Regency in order to support increased competitiveness of Pekalongan Regency.
\end{abstract}

Key words: public forests, gondorukem, industry cluster, SWOT analysis, analitycal network process (ANP)

\section{PENDAHULUAN}

Adanya globalisasi dan otonomi daerah membawa suatu konsekuensi logis bahwa tingkat kompetisi semakin tajam, baik di tingkat regional, nasional, dan internasional. Setiap daerah dituntut untuk lebih meningkatkan potensi-potensi yang dimilikinya dalam rangka peningkatan perekonomian dan daya saing daerah tersebut. Kabupaten Pekalongan merupakan salah satu kabupaten di Jawa Tengah yang berada di kawasan pantai utara jawa (pantura). Kabupaten ini merupakan daerah penghasil produk batik yang sudah dikenal secara umum, baik di Indonesia maupun di luar negeri. Jumlah industi yang bergerak di sektor industri batik mencapai 12.449 unit usaha, yang terdiri dari UKM hingga industri menengah dan tersebar di beberapa wilayah di Kabupaten Pekalongan. Jumlah yang besar tersebut menyebabkan timbulnya masalah baru, misalnya 
kelangkaan bahan baku, seperti gondorukem yang merupakan produk olahan dari getah pinus, seperti terlihat pada Gambar 1.

Kabupaten Pekalongan memiliki kawasa hutan yang relatif luas, di antaranya adalah hutan masyarakat yang telah ditanami pinus sejak 2004 dengan populasi sekitar 400.000 pohon, tetapi belum dimanfaatkan secara optimal. Hutan masyarakat ini tersebar di beberapa kecamatan bagian atas di Kabupaten Pekalongan, seperti Petungkriyono, Paninggaran, Kandang Serang dan Talun. Masyarakat hingga saat ini hanya menunggu hasil dari kayu saja karena Pemerintah Daerah belum memberikan aturan teknis pemanfaatan hasil non kayu dari hutan masyarakat tersebut. Padahal untuk menghasilkan kayu, pinus memerlukan waktu lebih dari 10 tahun dari usia tanam. Pengembangan ini akan mendatangkan banyak kemanfaatan, misalnya membuka peluang kesempatan kerja di pedesaan, menambah pendapatan dan mengurangi pengangguran, memperbaiki rantai pasok (supply chain) bahan baku batik berupa gondorukem dan wax/malam, serta mengembangkan pendayagunaan potensi sumber daya lokal pinus masyarakat secara berkelanjutan.

Beberapa hal yang perlu dilakukan dalam upaya tersebut, di antaranya mengidentifikasi dan menganalisa potensi hutan pinus masyarakat yang ada, menganalisis faktor-faktor yang mendukung dan menghambat upaya pengembangan, pengambilan keputusan, model kemitraan yang akan diterapkan, dan yang tidak kalah penting adalah upaya menemukan potensi-potensi baru yang mendukung peningkatan daya saing. Tujuan dari penelitian ini adalah untuk mengidentifikasi cara mengembangkan potensi hutan pinus masyarakat dan memperkuat daya saing komoditi gondorukem yang dihasilkan, baik pada pasar regional, nasional, maupun internasional.

\section{METODE}

Penelitian ini dilakukan di Kabupaten Pekalongan, dengan objek penelitian adalah hutan pinus rakyat. Pemilihan lokasi didasarkan pertimbangan bahwa, di Kabupaten Pekalongan terdapat potensi hutan pinus rakyat yang relative besar dengan permintaan hasilolahan getah pinus, khususnya gondorukem tinggi. Data yang dikumpulkan meliputi data primer dan data sekunder. Data primer mencakup data yang diperoleh melalui observasi langsung, wawancara dan penyebaran kuesioner. Data sekunder pada umumnya menyangkut keadaan umum lokasi dan data mengenai potensi pinus di Kabupaten yang didapatkan melalui studi literatur dan data dari Badan Pusat Statistik (BPS).
Terdapat beberapa metode yang digunakan dalam analisis pengembangan hutan pinus rakyat yang ada di Kabupaten Pekalongan menjadi gondorukem berbasis kemitraan, di antaranya : dalam identifikasi dan pengambilan keputusan dalam pengembangan potensi hutan pinus rakyat menjadi gondorukem berbasis kemitraan menggunakan analisis terhadap lingkungan internal yang berkaitan dengan kekuatan dan kelemahan dan eksternal yang berkaitan dengan peluang dan ancaman, analisis SWOT (Strength, Weakness, Opportunity, Threat) dan analisis pengambilan keputusan waktu pengembangan dengan menggunakan analisis BOCR (Benefit, Opportunity, Cost, Risk) dengan ANP (Analytical Network Process), di mana analisis tersebut mempertimbangkan aspek ekonomi, sosial, politik dan hukum, lingkungan, dan teknologi. Perumusan strategi pengembangan diawali dengan menganalisis faktor-faktor penting dalam pengembangan potensi hutan pinus rakyat dan dilanjutkan dengan penyusunan tindakan kunci.

\section{HASIL DAN PEMBAHASAN}

\section{Produk Gondorukem}

Gondorukem (resina colophonium) adalah olahan dari getah hasil sadapan pada batang tusam (Pinus). Gondorukem merupakan hasil pembersihan terhadap residu proses destilasi (penyulingan) uap terhadap getah tusam. Hasil destilasinya sendiri menjadi terpentin. Di Indonesia gondorukem dan terpentin diambil dari batang tusam Sumatera (Pinus merkusii). Di luar negeri sumbernya adalah $P$. palustris, $P$. pinaster, $P$. ponderosa, dan $P$. roxburghii. Nama lain gondorukem adalah Gum Rosin.

Gondorukem diperdagangkan dalam bentuk keping-keping padat berwarna kuning keemasan. Kandungannya sebagian besar adalah asam-asam diterpena, terutama asam abietat, asam isopimarat, asam laevoabietat, dan asam pimarat.

Penggunaannya antara lain sebagai bahan pelunak plester serta campuran perban gigi, sebagai campuran perona mata (eyeshadow) dan penguat bulu mata, sebagai bahan perekat warna pada industri percetakan (tinta) dan cat (lak). Selain itu, kegunaan gondorukem adalah untuk bahan baku industri kertas, keramik, plastik, cat, batik, sabun, tinta cetak, politur, farmasi, kosmetik dan lain-lain.

Di Indonesia, komoditi ekspor ini dihasilkan secara monopoli oleh PT Perhutani, terutama dari penanaman tusam di hutan pegunungan Jawa yang menjadi lahan konsesi BUMN itu. Adapun negara tujuan ekspor dari gondorukem di antarannya adalah negara-negara di benua Amerika, Asia, Eropa dan Afrika. 


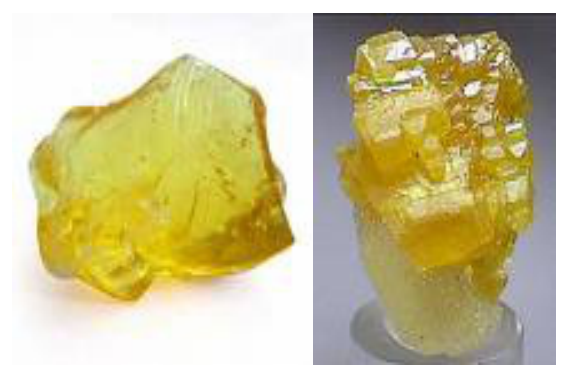

Gambar 1. Gondorukem atau Gum Rosin

\section{Analisis Lingkungan Internal dan Eksternal}

Pada Gambar 2 analisis lingkungan internal didapatkan beberapa hasil, di antaranya: a. Pemanfaatan lahan di Kabupaten Pekalongan belum sepenuhnya baik. proporsi lahan kritis juga masih relatif besar, sehingga apabila dimanfaatkan sebagai hutan produksi atau hutan masyarakat kemungkinan besar akan lebih bermanfaat, b. Produksi gondorukem yang dihasilkan oleh Kabupaten Pekalongan, yaitu PGT Paninggaran mengalami fluktuasi, sedangkan luas bidang sadapan yang dilakukan terhadap hutan pinus negara cenderung menurun sehingga pengembangan hutan pinus rakyat patut dipertmbangkan karena permintaan gondorukem relatif meningkat, baik dari dalam negeri maupun luar negeri, c. Berdasarkan hasil prediksi penyadapan getah pinus rakyat akan dapat meningkatkan pendapatan masyarakat daripada masyarakat hanya memanfaatkan kayunya saja, d. Dengan menggunakan analisis rantai nilai, dapat diketahui beberapa stakeholder yang terlibat dalam pengembangan hutan pinus dan strategi pengembangan yang akan dilakukan oleh Perhutani, sehingga akan mempermudah arah gerak pengembangan hutan pinus rakyat.

Sedangkan pada analisis lingkungan eksternal pada Gambar 2 didapatkan beberapa hasil, di antaranya: a. Jumlah industri batik yang berada di Kabupaten Pekalongan yang mencapai 12.459 unit usaha dapat menjadi pasar potensial bagi gondorukem ataupun getah pinus dari hutan masyarakat, b.Pengembangan hutan pinus rakyat diharapkan menjadi salah satu yang dapat berperan dalam penurunan angka pengangguran di Kabupaten Pekalongan, khususnya masyarakat sekitar hutan dan pihak-pihak yang terlibat dalam pengembangan hutan pinus rakyat menjadi gondorukem dari hulu ke hilir, c. Produksi getah pinus dan gondorukem Perhutani Unit I Jawa Tengah yang cenderung fluktuatif dapat menjadi peluang yang prospektif apabila pengembangan hutan pinus rakyat berjalan dengan baik, $d$. Dari analisis daya saing, pengembangan hutan pinus rakyat seharusnya dapat berjalan dengan baik apabila setiap elemen dan stakeholder mau bekerjasama, meskipun dalam upaya pengembangannya bayak ditemui hambatan, tetapi juga akan kita temui dukungan dan kesempatan yang baik.

\section{Analisis SWOT}

Dari analisis SWOT didapatkan bahwa kondisi potensi hutan pinus masyarakat menurut matrils internal-eksternal terletak pada kuadran Growth, Konsentrasi melalui integrasi vertikal. Posisi potensi tersebut menunjukkan bahwa potensi hutan pinus rakyat masih sangat berpeluang untuk tumbuh dan berkembang di masa yang akan datang. Selain itu, posisi tersebut akan menentukan rekomendasi kebijakan dan strategi yang akan dijalankan dalam rangka pengembangan agar hasil yang akan dicapai dapat optimal. Sedangkan menurut matriks SPACE pada Gambar 3, didapatkan posisi potensi tersebut terletak pada kuadran I atau sehat (agresif, komparatif). Posisi tersebut memungkinkan potensi yang ada untuk tumbuh dan berkembang.

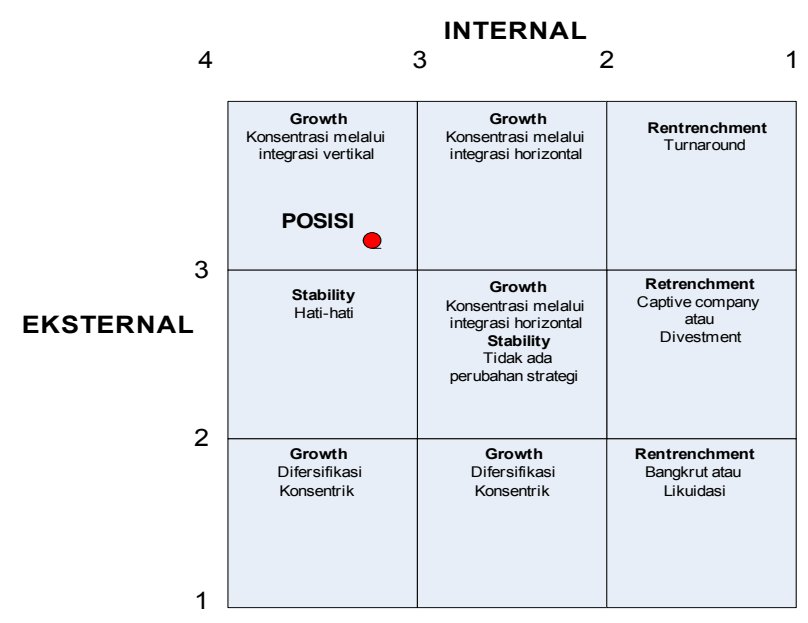

Gambar 2. Posisi Pengembangan Hutan Pinus Rakyat dengan Matrik Internal-Eksternal

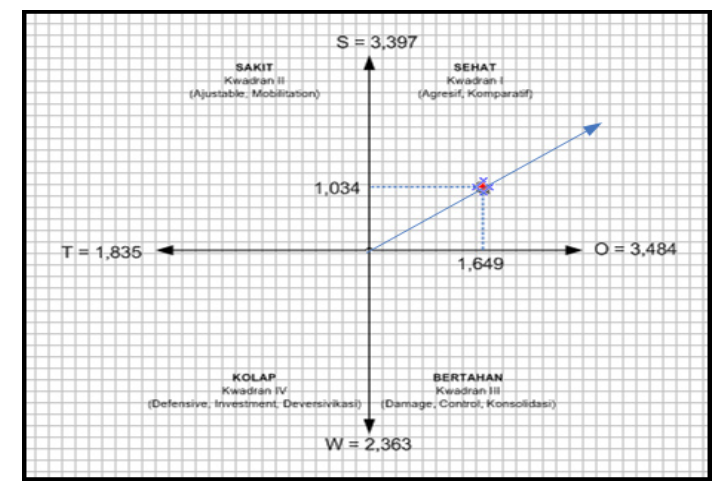

Gambar 3. Posisi Pengembangan Hutan Pinus Rakyat dengan Grafik SPACE 


\section{Analisis Pengambilan Keputusan menggunakan ANP dengan BOCR}

Pengambilan keputusan dengan menggunakan ANP dengan BOCR terhadap potensi hutan pinus rakyat di Kabupaten Pekalongan didapatkan 3 hasil seperti terlihat pada tabel 1 , yaitu kondisi umum (standard condition), pessimistic dan realistic. Untuk kondisi umum, ternyata bobot terbesar keputusan adalah alternatif lebih dari tahun 2009 yaitu sebesar 1,0336, untuk kondisi pesimis bobot terbesar adalah alternatif tidak layak dikembangkan, yaitu sebesar 6,5278 dan untuk kondisi realistis bobot terbesar adalah alternatif mulai tahun 2009 dengan bobot sebesar 1,0434. Dengan melihat perbedaan nilai bobot untuk tiap-tiap kondisi, maka keputusan diprioritaskan pada kondisi realistis karena lebih memungkinkan untuk dilakukan, sehingga keputusan yang diambil dari pengambilan keputusan mengenai pengembangan hutan pinus rakyat menjadi gondorukem berbasis kemitraan dapat dimulai pada tahun 2009. Tentunya keputusan ini tidak mutlak, melainkan harus didukung dengan pertimbangan yang lain dan strategi yang memungkinkan agar pelaksanaan pengembangan ini benar-benar memberikan manfaat yang optimal bagi pihak-pihak yang terlibat, khususnya masyarakat sebagai subjek dan objek keputusan tersebut.

Hasil pengolahan data yang dihasilkan dengan bantuan software Super Decisions 1.6.0 diperoleh hasil rekapitulasi sebagai berikut.

\section{Perumusan Strategi Pengembangan Potensi Hutan Pinus Rakyat}

Sebelum perumusan strategi, harus dilakukan analisis terhadap faktor penting yang mempengaruhi pengembangan potensi hutan pinus rakyat. Adapun di antara faktor-faktor penting tersebut adalah jaringan yang terlibat dan sistem kemitraan, sumber daya manusia dan pembagian peran, inovasi dan pengembangan, infrastruktur dan fasilitas, serta regulasi dan kebijakan dalam pengembangan hutan pinus rakyat di Kabupaten Pekalongan.

Setelah melihat beberapa faktor penting tersebut di atas dan dengan memperhatikan ketersediaan potensi sumber daya, kondisi iklim usaha, dan peluang bagi pengembangan yang tersedia (market) maka guna mewujudkan tumbuhnya usaha penyadapan pinus rakyat di Kabupaten Pekalongan dibutuhkan 3 tindakan kunci perlu dilakukan, yaitu: a. Potensi sumber daya lokal yang ada di Kabupaten Pekalongan harus dioptimalkan, sehingga pengembangan potensi hutan pinus rakyat dapat terlaksanan dengan optimal, b. Iklim usaha yang ada di Kabupaten Pekalongan untuk saat ini masih belum mendukung pengembangan potensi hutan pinus rakyat menjadi gondorukem berbasis kemitraan. Dalam rangka perbaikan iklim usaha yang ada di Kabupaten Pekalongan dilakukan beberapa kegiatan yang mendukung, c. Dengan mengembangkan tata niaga getah yang berkelanjutan, maka perkembangan di masa yang akan datang dari pengembangan ini akan lebih prospektif. Selain itu, dengan strategi ini akan memberikan manfaat kepada pihak atau stakeholder yang terlibat.

Adapun gambaran skema dari masing-masing tindakan kunci ditampilkan pada gambar 4-7 berikut.

\begin{tabular}{|c|c|c|}
\hline BENTUK KEGIATAN & LOKASI SASARAN & PELAKSANA \\
\hline $\begin{array}{l}\text { Kegiatan Sosialisasi tentang } \\
\text { potensi getah rakyat }\end{array}$ & \multirow{6}{*}{$\begin{array}{l}4 \text { Kecamatan } \\
\text { Potensial : } \\
\text { Petunglariyono } \\
\text { Paninggaran } \\
\text { Lebalkbarang } \\
\text { Tahun } \\
\text { Kandangserang }\end{array}$} & \multirow{6}{*}{\begin{tabular}{|l} 
- FPESD \\
Dishutbun \\
LSM \\
Kelompok Tani \\
HR/LMDH
\end{tabular}} \\
\hline & & \\
\hline Kegiatan & & \\
\hline Identifikasi/Pendataan Pinus & & \\
\hline Rakyat dan Usia Tanam & & \\
\hline \multirow{3}{*}{$\begin{array}{l}\text { Pendampingan pembentukan } \\
\text { Pokja/Pos Penampung Getah } \\
\text { di Tingkat Kelompok Tani di } \\
\text { Masing-masing desa }\end{array}$} & & \\
\hline & L & \\
\hline & OUT PUT & \\
\hline
\end{tabular}

$\varnothing$ Adanya pemahaman dari petari HR bahwa kegiatan penyadapan pinus di lahan rakyat merupakan kegiatan yang dapat memberkan keuntungan ekonomi

ø Terdatanya secara pasti jumlah populasi pinus di HR, serta potensi populasi Pinus yang siap sadap.

ø Munculnya inisiatip dari Petani Hutan Rakyat untuk memanfaatkan hasil getah pinus dengan melakukan kegiatan penyadapan.

Ø Terbentuknya kelomp ok petani penyadap pinus Hutan Rakyat di masing-masing lokasi sebagai bagian dari unit usaha kelembagaan Kelompok Tani HR/Koperasi Desa

Gambar 4. Skema Mobilisasi Potensi Sumber Daya Lokal Kabupaten Pekalongan

Tabel 1. Rekapitulasi Analisis BOCR Terhadap Alternatif Keputusan

\begin{tabular}{llcccccc}
\hline No & \multicolumn{1}{c}{ BOCR Alternatif } & B & O & C & R & $\begin{array}{c}\text { Standard } \\
(\mathbf{B} / \mathbf{C})\end{array}$ & $\begin{array}{c}\text { Pessimistic } \\
\mathbf{B} /(\mathbf{C} \mathbf{x} \mathbf{R})\end{array}$ \\
\hline 1 & Mulai tahun 2009 & 0,3808 & 0,3976 & 0,3847 & 0,3772 & 0,9899 & 2,6242 \\
$(\mathbf{B x O}) /(\mathbf{C x R})$
\end{tabular}




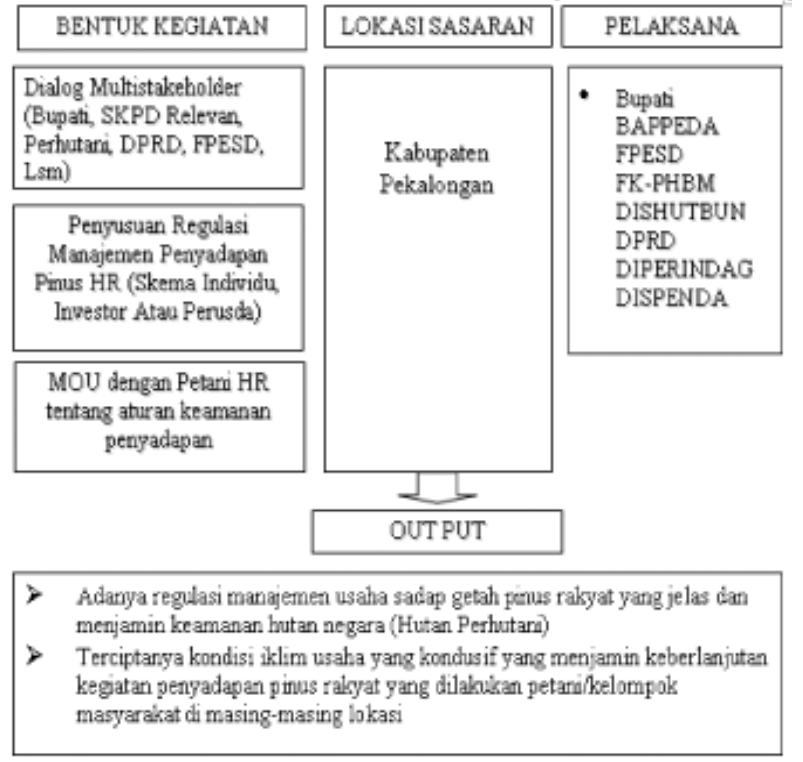

Gambar 5. Skema Perbaikan Iklim Usaha di Kabupaten Pekalongan

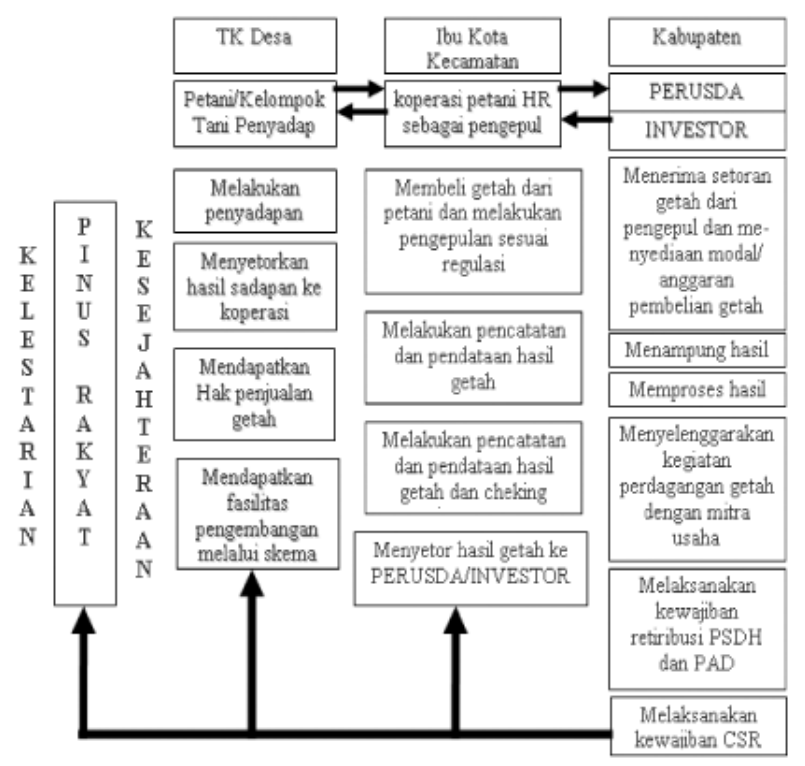

Gambar 6. Skema Pengembangan Tata Niaga Getah yang Berkelanjutan di Kabupaten Pekalongan

Dengan melihat harga getah pinus yang ada di pasar, yang salah satunya berasal dari Kabupaten Pacitan berharga Rp. 4650/kg, maka

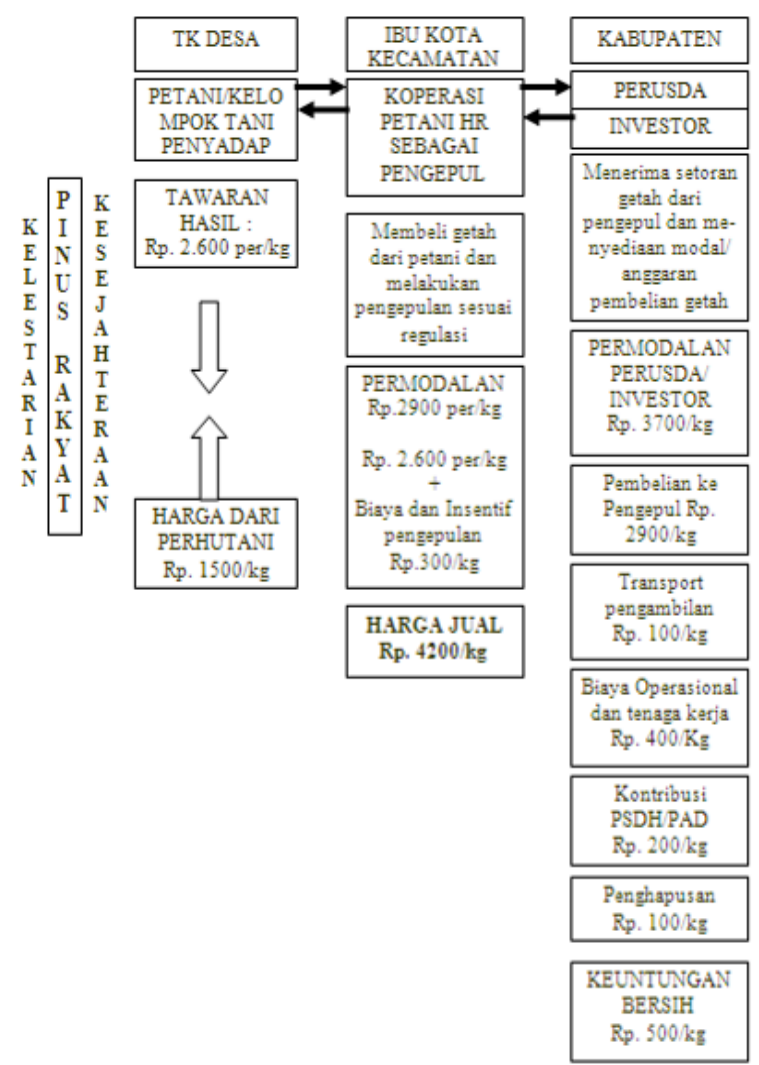

Gambar 7. Skema Perhitungan Keuntungan Setelah Perbaikan Tata Niaga Getah yang Berkelanjutan

dengan menggunakan indeks harga Perusda Rp. $4.200 / \mathrm{kg}$ akan memberikan kontribusi bagi pengusaha UKM Batik dalam penyediaan bahan mentah $=$ Gondorukem + Wax sebesar Rp. 450/kg.

\section{SIMPULAN}

Dari beberapa analisis yang telah dilakukan terhadap kemungkinan pengembangan hutan pinus rakyat menjadi gondorukem berbasis kemitraan di Kabupaten Pekalongan, maka potensi hutan pinus rakyat yang ada di Kabupaten Pekalongan secara umum memungkinkan untuk dilakukan pengembangan menjadi gondorukem berbasis kemitraan. Hal ini didukung oleh analisis lingkungan internal maupun lingkungan eksternal, analisis SWOT dan analisis

Tabel 2. Perhitungan Keuntungan Setelah Perbaikan Tata Niaga Getah yang Berkelanjutan

\begin{tabular}{cccccc}
\hline Tahun & $\begin{array}{c}\text { Jumlah Populasi } \\
\text { siap sadap }\end{array}$ & $\begin{array}{c}\text { Indeks Hasil per } \\
\text { hari (6-12 gr) }\end{array}$ & Hasil per tahun/kg & Indeks Keuntungan & $\begin{array}{c}\text { Nominal } \\
\text { pendapatan per Th }\end{array}$ \\
\hline 2009 & 180000 & 8 & 432000 & 500 & $\mathbf{2 1 6 . 0 0 0 . 0 0 0}$ \\
2010 & 225000 & 8 & 540000 & 500 & $\mathbf{2 7 0 . 0 0 0 . 0 0 0}$ \\
2011 & 275000 & 8 & 66000 & 500 & $\mathbf{3 3 0 . 0 0 0 . 0 0 0}$ \\
2012 & 325000 & 8 & 780000 & 500 & $\mathbf{3 9 0 . 0 0 0 . 0 0 0}$ \\
2013 & 400000 & 8 & 960000 & 500 & $\mathbf{4 8 0 . 0 0 0 . 0 0 0}$ \\
\hline
\end{tabular}


pengambilan keputusan menggunakan BOCR dengan ANP yang dilakukan. Pengembangan hutan pinus rakyat menjadi gondorukem ini diharapkan dapat menjadi sebuah solusi terhadap permasalahan yang terjadi di tengah masyarakat, khususnya pada masyarakat sekitar hutan di Kabupaten Pekalongan yang hingga saat ini belum optimal. Selain itu, pengembangan ini akan membawa implikasi positif terhadap pertumbuhan sektor industri yang lain, seperti industri batik dan meningkatkan daya saing daerah dalam kancah regional, nasional, atau bahkan internasional.

\section{DAFTAR PUSTAKA}

Abduh, Muhammad. 2007. Inovasi Teknologi dan Sistem Beton Pracetak di Indonesia: Sebuah Analisa Rantai Nilai. Yogyakarta: Prosiding Seminar dan Pameran HAKI 2007.

Astuti, Pudji, Tiena G. Amran, Herdono. 2008. Pemilihan Alternatif Pengelolaan Sampah dengan Metode ANP dan BOCR di Dinas Kebersihan Propinsi DKI Jakarta. Semarang: Prosiding INSAHP5, Teknik Industri UNDIP.

Badan Pusat Statistik (BPS) Kabupaten Pekalongan. 2006. Kabupaten Pekalongan Dalam Angka 2006. Semarang: BPS Kabupaten Pekalongan.

Badan Pusat Statistik (BPS) Propinsi Jawa Tengah. 2007. Jawa Tengah Dalam Angka 2007. Semarang: BPS Jawa Tengah.

BAPPENAS. 2004. Kebijakan Pembangunan Industri Nasional. Jakarta: BAPPENAS.

BAPPENAS. 2004. Tata Cara Perencanaan Pengembangan Kawasan untuk Percepatan pembangunan Daerah. Jakarta: Direktorat Pengembangan Kawasan Khusus dan Tertinggal, BAPPENAS.

BAPPENAS. 2004. Panduan Pembangunan Klaster Industri, untuk Pengembangan Ekonomi Daerah Berdaya Saing Tinggi. Jakarta: Direktorat Pengembangan Kawasan Khusus dan Tertinggal, BAPPENAS

Bidang PPKN. 2005. Upaya Optimalisasi Inventarisasi Tanah dan Bangunan Milik Negara pada Bidang Pembinaan Perbendaharaan dan Kekayaan Negara Kantor Wilayah XIII Direktorat Jenderal Perbendaharaan Semarang. Semarang: Departemen Keuangan Republik Indonesia, Direktorat Jenderal Perbendaharaan Kantor Wilayah XIII.

Djamhari, Choirul. 2006. Faktor-faktor yang Mempengaruhi Perkembangan Sentra UKM Menjadi
Klaster Dinamis. Jakarta: Infokop Nomor 29 Tahun XXII, Departemen Koperasi dan UKM.

Hayati, Sri; Suroso, Agus; Juwono, Budi. 2004. Analisis Strategi Bersaing Pada Pada BPR BKK Mandiraja Kabupaten Banjarnegara. Jakarta: SMART 34: Vol. 2 No. 1 Mei 2004.

http://www.netmba.com, diakses tanggal 15 juli 2008.

http://www.kbmink1.perumperhutani.com, diakses tanggal 15 Juli 2008.

http://www.wikipedia.com/gondorukem diakses tanggal 15 Juli 2008

Iskandarini. 2004. Analisis Pemecahan Masalah dan Pengambilan Keputusan. Medan: USU digital library, Fakultas Pertanian Universitas Sumatera Utara.

Porter, Michael E. 1990. The Competitive Advantage of Nations. New York: The Free Press.

Saaty, Thomas L. 1996. Decision Making With Dependence and Feedback: The Analytic Network Process. Pittsburgh: RWS Publications.

Sudrajat. 2007. Upaya Peningkatan Pelayanan Registrasi Mahasiswa Baru di Universitas Airlangga Surabaya Tahun 2008. Jakarta: Departemen Pendidikan Nasional, Pusat Pendidikan dan Pelatihan Pegawai, Diklat Kepemimpinan Tingkat III Angkatan 50 Tahun 2007.

Sulistiyani, Ambar Teguh. 2004. Kemitraan dan ModelModel Pemberdayaan. Yogyakarta: Penerbit Gava Media.

Simbolon, M.L., 2000. Kebijakan Baru Industri Nasional dan Strategi Peningkatan Daya Saing, Bandung: Prosiding Seminar kebijakan Industri dan Teknologi Pasca Krisis, Bandung, 18 April 2000, Bidang Khusus Tekno-Ekonomi Program Studi Teknik dan Manajemen Industri Program Pasca Sarjana ITB.

Taufik, Tatang A. 2005. Penguatan Daya Saing dengan Platform Klaster Industri: Prasyarat Memasuki Ekonomi Modern. Yogyakarta: Seminar dan Lokakarya Strategi dan Implementasi Pengembangan Daya Saing Ekonomi Daerah Dengan Pendekatan Lintas Sektoral.

USAID. 2006. Applying the Value Chain Framework to the Health Sector. USA: USAID.

Utomo, Tri Widodo W. 2000. Teknik Perumusan Strategi. Perwakilan LAN Jawa Barat, Bahan pelengkap Modul Lakip-2.

Wirabrata, H., 2000. Konsep dan Pentahapan Pelaksanaan Industrial Cluster. Jakarta: Dokumen C: No. 10. Departemen Perindustrian dan Perdagangan. 